\title{
Л.А. Чибиров
}

\section{ЕЩЕ РАЗ О ПЕРВОНАЧАЛЬНОМ ЯДРЕ НАРТИАДЫ}

\begin{abstract}
Вопрос о том, в какой этнокультурной среде возник Нартовский эпос, стал одним из наиболее дискуссионных в нартоведении. Дискуссии обострились после появления известной книги В. И. Абаева о нартовском эпосе, в которой было высказано мнение, что первоначальное ядро сказаний сформировалось в скифо-аланской среде. В то же время, согласно кониепиии полицентризма, выдвинутой Е.И. Крупновым, нартовские сказания явились результатом самобытного творчества сугубо кавказских народов. Концепиия спровоцировала появление трудов, в которых к адыго-абхазскому иентру первоначального бормирования эпоса прибавились ещце ингушский и карачаево-балкарский. Основываясь на трудах Абаева, Дюмезиля и др., автор статьи обоснованно доказывает существование лишь единого скифо-аланского ядра Нартиады с последующим заимствованием эпоса соседними народами.
\end{abstract}

Ключевые слова: нартовский эпос, ядро, полицентризм, национальные иентры, скифо-аланская основа.

В 1971 г. в научном издании АН Грузинской ССР «Мацне» («Вестник») была опубликована статья фольклориста из Абхазии А. Аншба «К спорам о происхождении первоначального ядра нартовского эпоса» явно претенциозного характера. Вскоре в том же журнале (1974, №1) достойный ответ ему дал Ю.С. Гаглойти. С тех пор прошло более четырех десятилетий, но проблема лишь еще более обострилась; кроме адыго-абхазов на роль создателя первоосновы эпоса стали претендовать и другие народы, у которых сохранились версии Нартиады. Это обстоятельство побудило нас выразить свое мнение по поводу обсуждаемой темы.

На вопрос, кому из народов Кавказа принадлежит нартовский эпос, В.И. Абаев дал четкий ответ: «Эпос принадлежит тому народу, среди которого он бытует. Это значит, что осетинские версии принадлежат осетинам, кабардинские - кабардинцам, абхазские - абхазам и т.д.» $[1,77]$.
Народы черпают свои песни и легенды не извне, а из сокровищ своей души, из своего исторического опыта, из своего жизненного уклада. Легко убедиться, что у каждого из народов Кавказа нартовские сказания по содержанию, бытовым реалиям, форме, поэтике, стилю, манере исполнения несут черты национальной фольклорной традиции, национального колорита $[1,77]$. Такого взгляда на эпос придерживались Л. Лопатинский, В. Миллер, Ж. Дюмезиль, Е. Мелетинский, Ф. Тордарсон, Ж. Грисвар, Ж. Шарашидзе, Л. Толстова и др. Эта один из подходов к вопросу, не вызывающий возражений.

Что касается генезиса эпоса, то до середины XX в. в ученом мире практически никто не ставил под сомнение, что нартовский эпос в основе своей осетинский и занесли его на Кавказ скифо-аланские племена, а бытование эпоса у соседних кавказских народов является следствием культурного заимствования. Эта концепция была 
выдвинута и аргументированно обоснована В.И. Абаевым, всесторонне подтверждена трудами выдающегося французского ученого, академика Ж. Дюмезиля. Основой же для их выводов послужило наибольшее богатство осетинских версий сказаний, довольно убедительные параллели, идущие от эпоса к скифо-аланскому и индоевропейскому миру и другие особенности. Ни во время жизни В. Абаева и Ж. Дюмезиля, ни в настоящее время нет ни одного ученого-нартоведа, кто бы своими трудами по мифологии и фольклору народов Кавказа затмил высокий научный авторитет этих корифеев нартоведения.

Выход книги В.И. Абаева «Нартовский эпос осетин» (1945) обострил интерес ученых-нартоведов к вопросу о корнях эпоса. И как следствие - появились полемические статьи о национальной первооснове эпоса, различные концепции происхождения эпоса, в том числе отдающие честь «изобретения» нартовских сказаний всем автохтонам Кавказа или одному из носителей версии эпоса.

Согласно концепции полицентризма (субстратно-кавказского происхождения эпоса), выдвинутой в середине 1950-х гг. Е. И. Крупновым, нартовские сказания - это результат самобытного творчества (а не заимствования) сугубо кавказских племен, носителей родственных языков, развившихся на основе единого кавказского субстрата [2, 19-20]. Своей концепцией Крупнов опроверг мнение о центрах формирования эпоса и практически подтолкнул к признанию еще и балкаро-карачаевского и вайнахского центров. На эту концепцию, т.е. на кавказские истоки эпоса, делается главный упор опопнентов гипотезы о принадлежности ядра эпоса скифо-аланскому миру. «Общие основы нартского эпоса были созданы почти всеми предками народов Северного Кавказа, и отчасти Южного Кавказа», - считает Аутлев [3, 218]. При этом не скрывается, что концепция Крупнова появилась в противовес позиции Абаева, что видно из следующих слов адыгского нартоведа А. Гутова: «В глубокой древности возможно исконно кавказское было обогащено элементами переднеазиатской хаттской, несколько позже - индоевропейской, то есть скифо-аланской, а еще позднее - тюрко-монгольской» $[6,12]$. В другой своей работе Гутов подытоживает: «Трудно предположить, что именно эти атрибуты индоиранской или же тюркско-монгольской общности стали основой сложения нартского эпоса - явления сугубо кавказского по характеру и природе» [4, 95].

Сторонники одного из направлений полицентризма считали, что ядро эпоса первоначально сформировалось в среде отдельного кавказского этноса, а именно: адыгские нартоведы этим этносом считали адыгов (Гадагатль), а абхазские - адыго-абхазов (Салакая). Было выдвинуто и мнение, согласно которому первоначальное ядро эпоса создано кавказцами или ираноязычными предками осетин (Аншба). На Сухумской конференции нартоведов (1963) было признано существование трех центров первоначального формирования нартовских сказаний: скифо-аланский, адыгский и абхазский. Пытаясь обосновать законность признания одного из центров формирования эпоса, некоторые ученые явно перебрали относительно древности национальных версиий. Всего две цитаты: «Абхазские вер- 
сии Нартиады по богатству сюжетов и образов и по архаичности превосходят все другие версии Нартиады» [5, 90], при этом возводя истоки к III-II тыс. до н.э., а некоторые исследователи даже относят время формирования нартовского эпоса к каменному веку (?!). По мнению же адыгского нартоведа Гадагатля, центральные мотивы и сюжеты Нартиады возникли в среде коренных кавказских племен, считая этой средой предков современных адыгов [10]. Нартовский эпос по характеру и природе является творением сугубо местной кавказской среды (независимо от языка, на каком она говорила) - считает Гутов $[4,95,97]$.

В последние годы громко заявлено о существовании и других центров формирования ядра эпоса. Карачаево-балкарские нартоведы считают нартовские сказания детищем киммерийцев, скифов, сарматов, алан, только они у них тюркоязычные. Ингушские нартоведы же утверждают, что эпос сформировался в древневайнахской среде и был создан горцами, а не ираноязычными степняками [7, 14-15, 56-73].

Обращает внимание и то, что внутри лагеря претендентов на новые центры формирования эпоса нет согласия. К примеру, А. Аншба исключает из числа «учредителей» эпоса карачаевцев и балкарцев, ссылаясь на его глубокую древность и сравнительно недавнее проникновение на Кавказ тюркоязычных народов [5, 90]. В свою очередь карачаево-балкарские нартоведы полагают, что гипотеза «субстратного» происхождения нартовского эпоса не имеет никаких оснований, как и предположение о «возникновении его ядра в абхазской, адыгейской или абхазоадыгейской среде» $[8,795]$. Что касается ингушских нартоведов, то они исходят из существовавшей якобы в древности «Великой Ингушетии» от Дагестана до Черноморского побережья, где проживали предки ингушей, последние и представляли субстрат проживавших там народов. Исходя из этого и вывод: осетинские нартовские сказания заимствованы пришлыми на Кавказ иранцами через ингушский субстрат (Дахкильтов). Первоначально Абаев поддержал «раздачу» центров формирования ядра эпоса, но затем вернулся к прежней позиции - иранского его происхождения.

Таким образом, погоня за заветным первенством в Нартиаде, без серьезных на то научных оснований, без учета мнений авторитетнейших ученых, вступила в новую фазу. Этот тот случай, когда, как сказал Абаев, национальная принадлежность ученого диктует ему его научную позицию и решения. Ученый справедливо считал, что такой наукой можно пренебречь как субъективной писаниной, не имеющей никакого научного значения.

Одновременно с попытками «обоснования» своих национальных центров, оппоненты скифо-аланского происхождения ядра эпоса в ход пускают необоснованные аргументы, чтобы отвести от иранских племен роль создателя первоосновы эпоса.

Между тем, в нартовском эпосе осетин прослеживаются следы эпоса древнейших индоевропейцев. Эта аксиома нашла отражение не только в трудах Абаева и Дюмезиля, но и других ученых-исследователей. Вот высказывания некоторых из них. «Этот народ (осетины. - Л. Ч.) такого широкого и притом древнего эпоса, подобно которому трудно встретить» $[11,18]$; «К ним (осетинским нартовским сказаниям. - 
Л. Ч.) по-видимому восходит большая часть былин Северного Кавказа» [12, 144]; «Много общего в религии, мифологии и эпосе осетин и других индоиранских народов, обитавших в Индии, Иране, Средней Азии. И теперь еще в национальном осетинском эпосе «Нарты» сохраняются сюжеты и образы, которые наводят на прямые соответствия в древней литературе Индии и Ирана. В нартах прослеживаются также многие черты, отражающие религиозные и мифологические представления, конкретные особенности быта и традиционных обычаев скифов» $[13,25]$; «Эти горцы (осетины. - Л. Ч.), последние потомки «иранцев Европы», были одним из самых консервативных индоевропейских народов, в частности они сохранили до наших дней обширный свод народных эпических сказаний, которые называются «Сказаниями о нартах»» $[14,13]$; «Не только российской, но и мировой наукой установлено, что ядро Нартиады восходит к древнеиранским фольклорным пластам I тыс. до н.э., но оформление эпоса, генезис главных героев и циклизация сказаний относится к I тыс. н.э. и принадлежат аланской этнической общности, с которой генетически связаны осетины» $[15,5]$; «Нартовский эпос восходит к аланам, в нем явно видны следы эпоса древних индоевропейцев» $[16,406]$. Список подобных цитат можно продолжить, привлекая мнение по данному вопросу других известных ученых: Тордарсона, Коларуссо, Мюллера, Гершевича, Левина, Мелетинского, Лебединского и др.

Признавая те или иные неоспоримые преимущества осетинской Нартиады, оппоненты скифо-аланского ядра эпоса пытаются объяснить их несущественными причинами. В частности, относительное богатство осетинских сказаний объясняют тем, что осетинская интеллигенция вовремя взялась за их записи (Тресков, Гадагатль). Причина же была в их относительно большем богатстве, о чем писал первый собиратель осетинских сказаний Дж. Шанаев. «Нужно признаться, что хотя поле для собирания «нартских сказаний» велико, даже слишком велико, - писал он, - однако, на этот раз я не мог явиться полноправным его хозяином, я не успел собрать столько сказаний, сколько желал» $[17,10]$.

Оппоненты скифо-аланского ядра признают и сюжетное богатство осетинских версий, но объясняют его не богатством полевого материала, а тем, будто до 60-х гг. ХХ в. у других версий Нартиады не было собирателей, которые бы интенсивно занимались сбором полевого материала, что также не соответствует действительности.

В качестве одной из претензий выдвигается довод: в национальных версиях много общего, повторяющегося. Но это слабый аргумент, ибо такие повторы - результат или этногенетических истоков, или длительного соседства носителей эпоса. Общность и близость эпических сюжетов и мотивов не всегда является результатом заимствований. В.И. Абаев объясняет их четырьмя причинами: генетическое родство, субстрат, типологическое единство и культурный обмен. Акцентируя внимание на культурном обмене, ученый пишет: «Исторические, археологические, этнографические, языковые данные согласно говорят о том, что такое общение между народами Кавказа было с давних пор весьма тесным, живым и интимным» $[18,36]$. Ученый допускает, что мотивы, образы, даже сюжеты 
могли возникнуть независимо в разных регионах, но абсолютно исключает, чтобы термин нарт или собственные имена Сатана, Урузмаг, Сослан, Созырко, Батраз, Сырдон и др. появились независимо в разных местах. И Абаев, безусловно, прав, ибо каждое из них, вне всякого сомнения, возникло в одном определенном месте, у одного определенного народа и отсюда уже распространилось среди других народов [18, 35]. Не могли же в глубине веков, в одно и то же время (скажем, где-то в Абхазии или в горном Дагестане, или на территории Алании) возникнуть идентичные эпические сюжеты и одинаковые имена героев самого эпоса.

Причина наибольшей популярности и распространенности осетинских версий видится оппонентами в высоком авторитете ученых - сторонников иранской версии (Дюмезиля, Абаева), что, на наш взгляд, совершенно несерьезно.

В стремлении умалить значение скифо-аланской природы ядра эпоса игнорируются как мнения по узловым вопросам нартоведения ученых с непререкаемым авторитетом, так и вышедшая за последние полстолетия целая серия трудов по нартоведению зарубежных коллег.

Не соответствует действительности довод, будто имена осетинских персонажей эпоса не являются древними. К тому же для выводов относительно происхождения эпоса и месте формирования его основного ядра собственные имена не могут привлекаться в качестве аргумента, поскольку имена могут многократно меняться. Необходим анализ, ориентированный на содержание сказаний, на раскрытие их сюжетов, образов, мотивов, на отраженные в них иде- ологические представления, верования, мифы, обряды.

Обвинения субъективного характера сыплются и на Абаева, работы которого будто бы проникнуты осетиноцентризмом, а авторитет ученого и его трудов считаются «виною» тому, что исследование чечено-ингушских нартовских сказаний попало под влияние «предвзятых концепций» $[9,415]$.

$\mathrm{He}$ выдерживают критики и утверждения, будто ираноязычные племена - пришлый элемент на Северном Кавказе, не коренной, «чужеродный». Между тем в период формирования нартовского эпоса (I тыс. до н.э. I тыс. н.э.) скифо-сармато-аланы были такими же кавказскими племенами, как и адыгские, вайнахские, дагестанские.

Оппоненты скифо-аланского ядра Нартиады, с одной стороны, утверждают, что эпос возник в автохтонной среде народов Кавказа, однако в то же время говорят о том, что проникшая в общекавказское этноязыковое и этнокультурное единство инородная культура (в том числе индоевропейская, скифоаланская) оказала такое мощное влияние, что появление представителей не исконно кавказских языковых анклавов изменило языковую и этнокультурную картину Кавказа. По сути, сторонники подобных суждений признают: привнесенная на Кавказ инородная культура, обладая более высоким уровнем развития, взяла вверх над местной.

Противники концепции скифоаланского ядра эпоса сознательно работают в однополярном пространстве, игнорируя ареальные связи осетинской Нартиады. Как показали исследования последних десятилетий, ареальные связи осетинской Нартиады оказались весьма существенными и позволяют 
проводить параллели с народами Евразии от Индии до Атлантического побережья. Среди народов Кавказа - носителей эпоса, контактировавших с широким кругом народов на значительных географических пространствах, истории известны лишь предки современных осетин - скифо-сармато-аланские племена.

По существу, национальные версии не могут конкурировать с осетинскими нартовскими сказаниями. Исключение составляют кабардинские (не адыгские, а именно кабардинские), ближе всех стоящие к осетинским по богатству сюжетов и другим характеристикам.

Между тем, сравнительный анализ двух основных версий Нартиады свидетельствует о скифо-аланской первооснове эпоса, чему есть подтверждения. У Дюмезиля не вызывало сомнений, что нартовский цикл у осетин отличается бо́льшим разнообразием мотивов и полнотой сюжетов в сравнении с черкесскими версиями $[19,34]$. О том, что кабардинские сказания уступают в количественном и качественном отношениях осетинским, писал еще в начале $\mathrm{XX}$ в. исследователь Рклицкий. О том, почему среди других кавказских народов адыги (особенно кабардинцы) оказались носителями наиболее богатой версии нартовских сказаний, обоснованно пишет известный фольклорист Е. Мелетинский. «Во-первых, основу аланского союза племен, кроме алан и других сарматских племен, составляли сарматизированные синдо-меотские племена, которые принято считать предками современных адыгских народов; во-вторых, аланы могли участвовать в этногенезе не только осетин, но и адыгских народов. В особенности это относится к кабардинцам, занявшим... значительную часть территории исторической Алании, ассимилировав при этом сохранившееся там аланское население... Остатки алан, вошедшие в состав кабардинской народности, могли сыграть значительную роль в распространении нартского эпоса; в-третьих, следует учитывать влияние фольклора... длительное взаимодействие народного творчества осетин, адыгов и других народов Кавказа» [20, 37, 226]. В унисон к сказанному выше звучит и мнение Ю.С. Гаглойти: «В наибольшей степени эти сказания были распространены у осетин и кабардинцев, причем осетинские сказания по своему богатству, полноте, цикличности, насыщенности фольклорно-историческим материалом намного превосходят кабардинские» [21, 186]. Кабардинские версии Нартиады не содержат многое из составляющих основ эпоса, coхранившееся в первозданном виде в осетинских нартовских сказаниях.

Много общего в религии, мифологии и эпосе осетин и других индоиранских народов, обитавших в Индии, Иране, Средней Азии. И теперь еще в национальном осетинском эпосе «Нарты» сохраняются сюжеты и образы, которые находят прямые соответствия в древней литературе Индии и Ирана. В нартах прослеживаются также многие черты, отражающие религиозные и мифологические представления, конкретные особенности быта и традиционных обычаев скифов $[13,25]$.

Самый объективный подход при установлении национального приоритета нартовских сказаний предусматривает учет всех существующих характерных признаков, «определителей» эпического произведения: архаичность, наибольшая полнота и цикличность; 
наибольшее сюжетное богатство; более высокое художественное совершенство; степень развития ареальных связей, установленных в ходе сопоставительного анализа, компетентное мнение научных авторитетов.

Понятно, что наличие одного или двух из перечисленных факторов (древнейшая основа, богатство эпоса и др.) не дает еще оснований объявить какой-либо народ создателем эпоса. Однако в случае с осетинскими нартовскими сказаниями положение иное. Только они характеризуются всем комплексом перечисленных «определителей»: наибольшее сюжетное богатство, художественное совершенство, сказания представлены в наиболее завершенном виде, прошли полный этап циклизации, сохранили структуру, они на переднем плане и по количеству ярких эпических персонажей. Эпос осетин характеризуется не только богатством и полнотой, но и яркими скифо-алано-осетинскими параллелями, ареальными связями с эпическим миром народов на просторах Евразии. Только по осетинским нартовским сказаниям можно судить о начале и конце эпоса. Весьма существенное свидетельство ираноязычия ядра эпоса - это соответствие осетинской Нартиады теории трехфункционального деления и полное отсутствие этого в других версиях эпоса. Это деление находит все новые подтверждения в фольклоре и этнографии многих народов индоевропейского круга.

Bce перечисленные характерные признаки, имеющие место в совокупности в осетинской Нартиаде, отмечаются не только осетинскими нартоведами. «По общему объему накопленного материала, завершенности и богатству сюжетных мотивов и циклов, по худо- жественным достоинствам, обилию антропонимов, этнонимов и топонимов и другим эпическим параметрам наиболее полными и завершенными оказались осетинские нартовские сказания», - считает балкарский нартовед Джуртубаев [8, 343]. При наличии нартовских сказаний у всех горских народов «ни один из них не знает ни начала ни конца нартов, не говоря о том, где и как родились нарты, кто жил до них и кто после, тогда как у осетин излагается все от начала до конца» $[28,373]$. Эти слова, высказанные М. Тугановым в 20-х гг. прошлого столетия, остаются в силе по настоящее время.

О многих преимуществах осетинской Нартиады выше было сказано, но ими она не ограничивается. В осетинском эпосе пять сформировавшихся (завершенных) и развитых эпических циклво, в то время как в адыго-абхазском сохранился лишь один цикл (Coсруко, Сасрыквы). При этом, вопреки утверждению, их аналог в осетинском (Сослан) не уступает ни по колоритности образа, ни по архаичности. В других версиях эпоса практически отсутствуют образы таких колоритных центральных фигур, как героический Батраз и хитроумный Сырдон; без них осетинские сказания потеряли бы свой блеск. Параллели к образам Сослана, Батраза, Сырдона, Сатаны довольно ярко прослеживаются в древнем индоевропейском мифологическом пространстве, а в кавказских версиях эпоса видна лишь их бледная тень.

Нет ни одной национальной версии Нартиады, где бы в той или иной степени не прослеживались алано-осетинские элементы и влияния. В то же время об обратных влияниях практически ничего не известно, если не считать нали- 
чие в осетинском кабардинизированного Сослана - Созырко.

О том, что эпос возник и развивался в одной этнической среде, свидетельствует аланский моноцентризм. В период окончательного оформления эпоса (I-XIII вв.) Алания была единственным государственным образованием в Центральном Предкавказье и отличалась политической зрелостью и многочисленностью населения. Этим фактом аланского моноцентризма объяснимы неодинаковая степень распространения и влияния эпоса среди соседних народов, входившие в политическую организацию алан. В частности, у кабардинцев, географически ближайших соседей алан, нартовские сказания сохранились относительно лучше других кавказоязычных народов. Однако чем дальше на запад от Кабарды, тем более (у тех же адыгских и абхазо-абазинских племен) эпос уступает кабардинскому, выглядит слабее (у убыхов, живших у побережья моря, его вовсе не было). К востоку же от аланского моноцентра, у ингушей, сказания представлены более богато, чем у чеченцев, расположенных восточнее от них, а еще далее, в Дагестане, сказания сохранились лишь в отдельных сказочных сюжетах. Вывод напрашивается сам собой: по мере отдаления от центра формирования эпоса к западу и к востоку влияние сказаний затухало. Такова логика вещей: Алания (Осетия) представляла собой как бы эпицентр нартовских сказаний, степень распространения которых уменьшалась по мере удаления от этого центра. Это обстоятельство подчеркивает и У. Далгат: «По мере удаления от их центра распространения (Осетия, Кабарда) в них наблюдается не только забвение традиционных нартских имен, но и значительная деформация или полное исчезновение нартских сюжетов» [22, 163]. В унисон к сказанному выше и следующие слова Дюмезиля: «Нартовский эпос, ядро которого, несомненно, сложилось у предков осетин, был воспринят большей частью их кавказских соседей и даже соседями их соседей; в общих чертах его заимствовали на западе абхазцы, черкесы, отдельные поселения балкарцев, на северо-востоке чеченцы, ингуши и карачаевцы. У этих разных народов нарты зажили иной жизнью» [23, 117].

Таким образом, теория аланского моноцентризма не оставляет места для сомнения: нартовский эпос возник и развивался в одной этнической среде, отражал мифологию и историю одного большого народа, а затем уже распространился у соседних народов.

О том, что в нартовском эпосе послеживаются следы эпоса древнейших индоевропейцев, индоариев и иранцев, писали многие видные ученые, далекие от национальных пристрастий. В их числе: Г. Бонгард-Левин, Э. Грантовский, К. Литтлтон, Л. Малкор, Т. Хейердал, что неопровержимо свидетельствует о том, что нет осетинской теории происхождения эпоса, нет адыгской, а есть только научно обоснованная теория. Нартовские сказания - это дань эпической традиции северо-восточной группы иранских народов - скифов, сарматов, алан и их преемников - осетин.

В том, что ядро эпоса - скифоаланское и пришло из Осетии, был твердо уверен и отстаивал многократно самый выдающийся авторитет в нартоведении Ж. Дюмезиль. Французский академик неоднократно подтверждал, что соседние народы (адыги, абхазы, 
вайнахи) лишь обогатили сказания новыми эпизодами и новыми героями, «восприняли эпос у осетин, исказив в нем как раз то, что было специфически осетинским, скифским». Ему же принадлежат ниже приведенные слова, которые, как ни стараются игнорировать оппоненты скифо-аланского ядра эпоса сегодня, вынуждены будут признать завтра: «Именно у осетин, и, без сомнения, частично уже у их далеких предков сформировалось ядро эпопеи, ее главные персонажи. Я знаю, что публикуя это суждение, я огорчу моих черкесских и абхазских друзей, но истина дороже; в своей основе нартский эпос - осетинский». И далее: «Он был воспринят многими соседними народами... многообразно трансформировался с потерями и обогащениями, приобретая в особенности различную моральную окраску...» $[19,169]$.

Между тем в том, что эпос заимствован у осетин соседними народами, были убеждены не только Абаев и Дюмезиль, но и другие известные специалисты. Вот высказывания некоторых из них: «Многие народы Кавказа, как позднейшие пришельцы, заимствовали некоторые типы героев-нартов у кабардинцев или нашли их на новой родине, раньше их населенной осетинами» [24, 167]; «Местная этническая неираноязычная среда оказалась творчески бесплодной и лишь питательной средой, в которой позднее пышным цветом расцвели занесенные иранскими племенами - скифами, сарматами, и особенно аланами, знаменитые нартские сказания» [25, 163]; «Эти сказания северных осетин в действительности распространились среди их соседей (черкесов, татар, аб- хазцев, чеченцев, ингушей), которыми они переняты, зачастую адаптированы, смешаны или переделаны» $[14,13]$; «Нартовский эпос осетин, последних потомков скифской ветви ариев, сохранил... трехфунциональную схему очевидного индоевропейского происхождения. Однако их соседи, автохтонное население Кавказа, которые не являются индоевропейцами, утратили суть этой культуры даже в том случае, когда они разрабатывали свой эпос по образцу осетинского. Они берут у него героев - легендарных нартов, которые зачастую сохраняют те же приключения и схожие судьбы...» $[26,8]$; «Осетины... носители нартовского эпоса. Это собрание героических сказаний... осетины делят со своими западными неиндоевропейскими соседями- черкесами, убыхами, абазинцами и абхазами, а также в некоторой степени с южными соседями - сванами и грузинскими горцами, с восточными - чечено-ингушами, дагестанцами, и, наконец, некоторыми малыми тюркскими народностями, как например, карачаевцы и балкарцы» [27, 15]; «Осетины сохранили национальный эпос - цикл сказаний о богатырях-нартах, который был частично заимствован у них соседними народами (абхазами, адыгами, карачаевцами и рядом других народов Кавказа)» [16, 431].

В свете вышеизложенного остается в силе основополагающее заключение Абаева о генезисе сказаний о нартах: «Истоки нартовского эпоса ведут к легендам североиранских племен скифов, сарматов, алан» $[1,79]$.

Таковы факты, такова действительность, с которой следует считаться всем тем, кому дорога научная истина. 
1. Абаев В. И. Нартовский эпос осетин. Цхинвали, 1982.

2. Крупнов Е.И. О времени формирования основного ядра нартского эпоса у народов Кавказа // Сказания о нартах - эпос народов Кавказа. М., 1969. С. 15-29.

3. Аутлев П. У. Об одном «новом направлении» в нартоведении // Известия СОНИИ. 1966. Т. ХХVI. С. 205-219.

4. Гутов А. М. Народный эпос: традиция и современность. Нальчик, 2009.

5. Аншба А.А. К спорам о происхождении первоначального ядра нартского эпоса // Мацнэ. Серия языка и литературы. 1971. № 4. С. 85-92.

6. Гутов А. М. Рубежи веков и эпос о нартах. Нальчик, 2011.

7. Мужухоев М.Б. Ингуши. Страницы истории, вопросы материальной и духовной культуры. Саратов, 1995.

8. Джуртубаев М. Ч. Происхождение нартского эпоса. Нальчик, 2013.

9. Дахкильтов И.А. Ингушский нартский эпос. Тексты, исследование. Нальчик, 2012.

10. Гадагатль А. М. Героический эпос «Нарты» и его генезис. Краснодар, 1967.

11. Марков Е. Л. Очерки Кавказа. Картины кавказской жизни, природы и истории. СПб. - М., 1887.

12. Лопатинский Л. Г. Предисловие // Сборник материалов для описания местностей и племен Кавказа. 1891. Вып. 12. С. I-II.

13. Бонгард-Левин Г. М., Грантовский Э. А. От Скифии до Индии. Древние арии: мифы и история. М., 1983.

14. Грисвар Ж. Мотив меча, брошенного в озеро: смерть Артура и смерть Батрадза // Эпос и мифология осетин и мировая культура. Владикавказ, 2003. С. 6-81.

15. Кузнецов В.А. Предисловие // Г. Б. Романова. Нартский эпос и история осетинского народа. Владикавказ, 2014. С. 5-8.

16. Хейердал Т., Лиллиестрём П. В погоне за Одином. М., 2008.

17. Шанаев Дж. Осетинские народные сказания // Сборник сведений о кавказских горцах. 1871. Вып. 5. Отд. II. С. 1-37.

18. Абаев В. И. Проблемы нартского эпоса // Нартский эпос: Материалы совещания 19-20 октября 1956 г. Орджоникидзе, 1957. С. 22-36.

19. Дюмезиль Ж. Осетинский эпос и мифология. Владикавказ, 2001.

20. Мелетинский Е. М. Место нартских сказаний в истории эпоса // Нартский эпос: Материалы совещания 19-20 октября 1956 г. Орджоникидзе, 1957. С. 37-73.

21. Гаглойти Ю. С. Избранные труды. Цхинвал, 2010. Т. 1.

22. Далгат У.Б. К вопросу о нартском эпосе у народов Дагестана // Нартский эпос: Материалы совещания 19-20 октября 1956 г. Орджоникидзе, 1957. С. 154-174.

23. Дюмезиль Ж. Скифы и нарты. М., 1990.

24. Миллер В.Ф. Кавказско-русские параллели // Этнографическое обозрение. 1891. №3. С. 166-189.

25. Мелетинский Е. М. Происхождение героического эпоса. Ранние формы и архаические памятники. М., 1963.

26. Шарашидзе Ж. Индоевропейская память Кавказа. Владикавказ, 2004. 
27. Коларуссо Дж. Предисловие // К. С. Литтлтон, Л. А. Малкор. От Скифии до Камелота. Владикавказ, 2007.

28. Туганов М. С. Кто такие нарты? // Известия Осетинского научно-исследовательского института краеведения. 1925. Вып. 1. С. 371-378.

Chibirov, Lyudvig A. - V.I. Abaev North Ossetian Institute for Humanitarian and Social Studies of the Vladikavkaz Scientific Centre of RAS; L.chibirov@mail.ru

\section{AGAIN ON THE NARTS' SAGAS INITIAL CORE.}

Keywords: Nart epic, kernel, polycentricity, national centres, Scythian-Alanian basis.

One of the most contested issues in Nartiada is in what ethno-cultural environment the formation of the initial core of the epic had been taking place. The disputes go back to the publication of V.I. Abaev's famous book on Narts' epics, where the Scythian-Alanian environment was clearly marked as the original core legends had been formed in. In accordance with E. I. Krupnov's concept of polycentricity, Narts'sagas are regarded as the result of original creativity of the Caucasian peoples. The concept provoked the emergence of the works in which to the Adyghe-Abkhazian basis of the formation of the epic were consecutively added also the Ingush and Karachay-Balkar centers. The works of Abaev, Dumezil and others give the author profound basis to argue that there is a single Scythian-Alanian core of the formation of the Narts' Sagas with the subsequent borrowing of the epic by the neighboring peoples.

\section{REFERENCES}

1. Abaev, V. I. Nartovskiy epos osetin [Nart epic of the Ossetians]. Tskhinvali, Iryston, 1982. $106 \mathrm{p}$.

2. Krupnov, E. I. O vremeni formirovaniya osnovnogo yadra nartskogo eposa u narodov Kavka$z a$ [About the time of the formation of the main core of the Nart epic among the peoples of the Caucasus]. Skazaniya o nartakh - epos narodov Kavkaza [Tales of the Narts - the epic of the peoples of the Caucasus]. Moscow, Nauka, 1969, pp. 15-29.

3. Autlev, P. U. Ob odnom «novom napravlenii»v nartovedenii [About one «new direction» in the Nart Studies]. Izvestiya Severo-Osetinskogo nauchno-issledovatel'skogo instituta [Proceedings of the North Ossetian Research Institute]. 1966, vol. XXVI, pp. 205-219.

4. Gutov, A. M. Narodnyy epos: traditsiya i sovremennost' [Folk epic: tradition and modernity]. Nalchik, Kabardino-Balkarian Institute for Humanities, 2009. 225 p.

5. Anshba, A.A. K sporam o proiskhozhdenii pervonachal'nogo yadra nartskogo eposa [To disputes about the origin of the initial core of the Nart epic]. Matsne. Seriya yazyka i literatury [Matsne. Language and literature series]. 1971, no.4, pp. 85-92.

6. Gutov, A.M. Rubezhi vekov i epos o nartakh [The turns of the centuries and the epic of the Narts]. Nalchik, Kabardino-Balkarian Institute for Humanities, 2011.36 p.

7. Muzhuhoev, M. B. Ingushi. Stranitsy istorii, voprosy material'noy i dukhovnoy kul'tury [The Ingush. Pages of history, issues of material and spiritual culture]. Saratov, Detskaya kniga, 1995. $128 \mathrm{p}$.

8. Dzhurtubaev, M.Ch. Proiskhozhdenie nartskogo eposa [The Origin of the Nart epic]. Nalchik, Tetragraf, 2013. 804 p.

9. Dakhkilgov, I. A. Ingushskiy nartskiy epos. Teksty, issledovaniye [Ingush Nart epic. Texts, study]. Nalchik, Tetragraf, 2012. 602 p.

10. Gadagatl, A. M. Geroicheskiy epos «Narty» i yego genesis [The heroic epic «Narts» and its genesis]. Krasnodar, Knizhnoye izdatel'stvo, 1967. 422 p.

11. Markov, E. L. Ocherki Kavkaza. Kartiny kavkazskoy zhizni, prirody $i$ istorii [Essays on the 
Caucasus. Pictures of Caucasian life, nature and history]. St. Petersburg - Moscow, Tovarishchestvo M. O. Vol'f, 1887. 704 p.

12. Lopatinsky, L. G. Predislovie [Foreword]. Sbornik materialov dlya opisaniya mestnostey i plemen Kavkaza [Collected materials for the description of areas and tribes of the Caucasus]. 1891, iss. 12, pp. I-II.

13. Bongard-Levin, G. M., Grantovsky, E. A. Ot Skifii do Indii. Drevniye arii: mify i istoriya [From Scythia to India. Ancient arias: myths and history]. Moscow, Mys l', 1983. 206 p.

14. Grisvard, J. Motiv mecha, broshennogo v ozero: smert' Artura i smert' Batradza [The motif of the sword thrown into the lake: the death of Arthur and the death of Batradz]. Epos i mifologiya osetin i mirovaya kul'tura [Epos and mythology of Ossetians and world culture]. Vladikavkaz, Ir, 2003, pp. 6-81.

15. Kuznetsov, V. A. Predislovie [Foreword]. G. B. Romanova. Nartskiy epos $i$ istoriya osetinskogo naroda [G. B. Romanova. Nart epic and history of the Ossetian people]. Vladikavkaz, 2014, pp. 5-8.

16. Heyerdahl, T., Lillieström, P. $V$ pogone za Odinom [The search for Odin]. Moscow, Menedzher, 2008. 430 p.

17. Shanaev, Dzh. Osetinskiye narodnyye skazaniya [Ossetian folk tales]. Sbornik svedeniy o kavkazskikh gortsakh [Collected information about the Caucasian mountaineers]. 1871, iss. 5, part II, pp. 1-37.

18. Abaev, V.I. Problemy nartskogo eposa [The problems of the Nart epic]. Nartskiy epos: Materialy soveshchaniya 19-20 oktyabrya 1956g. [The Nart epic: Proceedings of the session, October 19-20, 1956]. Ordzhonikidze, Severo-Osetinskoye knizhnoye izdatel'stvo, 1957, pp. 22-36.

19. Dumézil, G. Osetinskiy epos i mifologiya [Ossetian epic and mythology]. Vladikavkaz, Nauka, 2001. 278 p.

20. Meletinsky, E. M. Mesto nartskikh skazaniy v istorii eposa [Place of Narts legends in the history of the epos]. Nartskiy epos: Materialy soveshchaniya 19-20 oktyabrya 1956g. [The Nart epic: Proceedings of the session, October 19-20, 1956]. Ordzhonikidze, Severo-Osetinskoye knizhnoye izdatel'stvo, 1957, pp. 37-73.

21. Gagloyti, Yu. S. Izbrannyye trudy [Selected works]. Tskhinval, 2010, vol. 1. 814 p.

22. Dalgat, U. B. K voprosu o nartskom epose u narodov Dagestana [On the question of the Nart epic of the peoples of Dagestan]. Nartskiy epos: Materialy soveshchaniya 19-20 oktyabrya 1956g. [The Nart epic: Proceedings of the session, October 19-20, 1956]. Ordzhonikidze, Severo-Osetinskoye knizhnoye izdatel'stvo, 1957, pp. 154-174.

23. Dumézil, G. Skify i narty [Scythians and Narts]. Moscow, Nauka, 1990. 229 p.

24. Miller, V.F. Kavkazsko-russkiye paralleli [Caucasian-Russian parallels]. Etnograficheskoye obozreniye [Ethnographic review]. 1891, no. 3, pp. 166-189.

25. Meletinsky, E.M. Proiskhozhdeniye geroicheskogo eposa. Ranniye formy i arkhaicheskiye pamyatniki [The origin of the heroic epic. Early forms and archaic monuments]. Moscow, Izdatel'stvo vostochnoy literatury, 1963. $462 \mathrm{p}$.

26. Sharashidze, Zh. Indoyevropeyskaya pamyat' Kavkaza [Indo-European memory of the Caucasus]. Vladikavkaz, Ir, 2004. 79 p.

27. Colarusso, J. Predislovie [Foreword]. K. S. Littlton, L.A. Malkor. Ot Skifii do Kamelota [K. S. Littlton, L. A. Malkor. From Scythia to Camelot]. Vladikavkaz, Proekt-Press, 2007. 304 p.

28. Tuganov, M.S. Kto takiye narty? [Who are the Narts]. Izvestiya Osetinskogo nauchno-issledovatel'skogo instituta krayevedeniya [Proceedings of the Ossetian Research Institute of Local History]. 1925, iss. 1, pp. 371-378. 